which was not quite obvious, but a probe entered only a very short way. It certainly did not penetrate to the spine and we finally came to the conclusion that it had nothing to do with her disease. The tenderness of the lower limbs, the flaccid paraplegia, with absence of the knee-jerks, coupled with the peculiar mental state, suggested a peripheral neuritis, but this would hardly account for the paralysis of the bladder, still less for the retraction of the head and rigid spine. A diagnosis of meningitis seemed best to cover the facts. A lumbar puncture was made on two occasions but no fluid was obtained. Probably the interior of the meninges was not reached, seeing that post mortem an abundance of pus was found there. The course of the case was as follows. The retraction of the head improved so that by the end of June it had almost disappeared. The sleeplessness, very troublesome at first, yielded slowly to regular doses of bromides. She remained odd mentally, though she improved slowly in this respect. In the course of the first three weeks the paralysis spread to the hands. She complained of "pins and needles " in them and loss of power so that she could not feed herself. The bladder did not recover, but instead of dribbling from over-distension, as on admission, there was reflex incontinence-i.e., the urine passed involuntarily at intervals. In spite of all care some cystitis developed. The patient became very wasted, as generally happens in prolonged cases of meningitis. Nevertheless, after about six weeks' time she appeared to be improving slightly and I began to think she might eventually recover when events took place for which we were not prepared and which brought about her death. On August 10th there was a discharge of greenish pus per rectum, about eight ounces in amount. A rectal examination made a few days later disclosed a boggy patch on the posterior aspect of the gut. The pus continued to discharge. Early on the 21st she complained of abdominal pain; the abdomen was found to be more distended than usual, resistant, tender, and dull in the flanks. The pulse, never good, became steadily more frequent and feeble and she died that morning.

Necropsy. - The post-mortem examination (made by $\mathrm{Dr}$. Horton Smith Hartley) explained the manner of her death. The brain and its membranes were natural, save that over the cerebellum and the medulla the pia mater was possibly more opaque than usual. The spinal cord showed a purulent meningitis most marked in the lower part of the cord but extending in a less degree up to the cervical region. The tube of the dura mater was full of pus. This pus had made its way along the nerve roots and set up irregular abscesses behind the spinal column in the muscles of the lower dorsal and lumbar regions, on either side of the spinal column anteriorly, and also a large abscess behind the rectum. This last-mentioned abscess had burst into the rectum a little way above the anus, thereby producing the discharge of pus per anum (August 10th), and into the general peritoneal cavity at the level of the brim of the pelvis, thereby setting up a peritonitis from which the patient died. There was pus in the bladder and in the pelvis of the kidneys and the mucous membrane of both these parts was injected. The bones of the spinal column, the sacrum, and the sacro-iliac joints were carefully examined but no source of infection could be found such as might have produced a meningitis. The conclusion arrived at, therefore, was that there was a primary spinal meningitis with secondary abscesses, one of which had perforated the peritoneum and so caused death. The pus from within the meninges of the cord yielded a pure culture of staphylococcus pyogenes albus.

\section{A CASE OF EXCISION OF THE RECTUM FOR CARCINOMA RECTI.}

By F. .C. Wallis, M.B., B.C. Cantab., F.R.C.S. Eng. SURGEON TO CHARING CROSS HOSPITAL, ETC.

THE following case is so satisfactory in the ultimate result obtained that it seems worth while to record it, having regard to the fact that the practical results in these opera. tions are often so disheartening.

A man, aged 72 years, was admitted to St. Mark's Hospital on Jan. 25th, 1904, suffering from carcinoma recti. The patient had always enjoyed good health until eight months previously to admission when he noticed a "stoppage of water" which was followed by diarrhœa. The diarrhoa had persisted ever since and was accompanied by loss of blood. There was no offensive discharge or any great pain. He had lost 21 pounds in weight during the last three months. He had always been a strong healthy man. Rectal examination revealed an ulcerated growth, mainly in the posterior wall but extending also on to the anterior wall, commencing about three and a half inches from the anus. The growth appeared to be fixed to the deeper tissues. It was decided to prepare the patient for operation and to examine him again under an anæsthetic, being prepared to remove the growth if it was thought possible to do so.

FIG. 1.

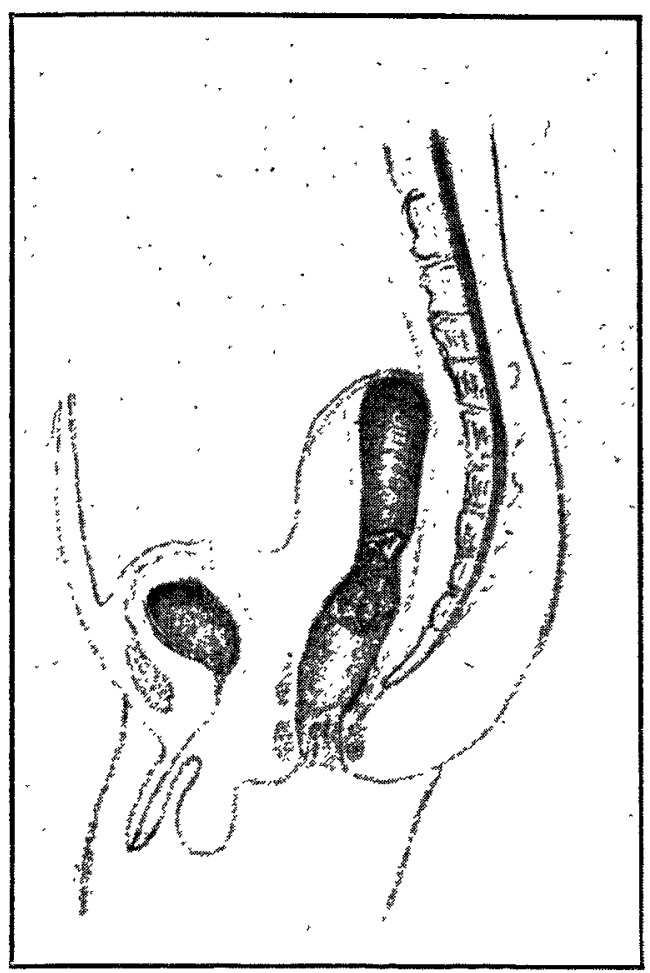

Sagittal section of pelvis showing diagramatically the condition before the first operation. Growth seen in rectum.

F゙IG. Z.

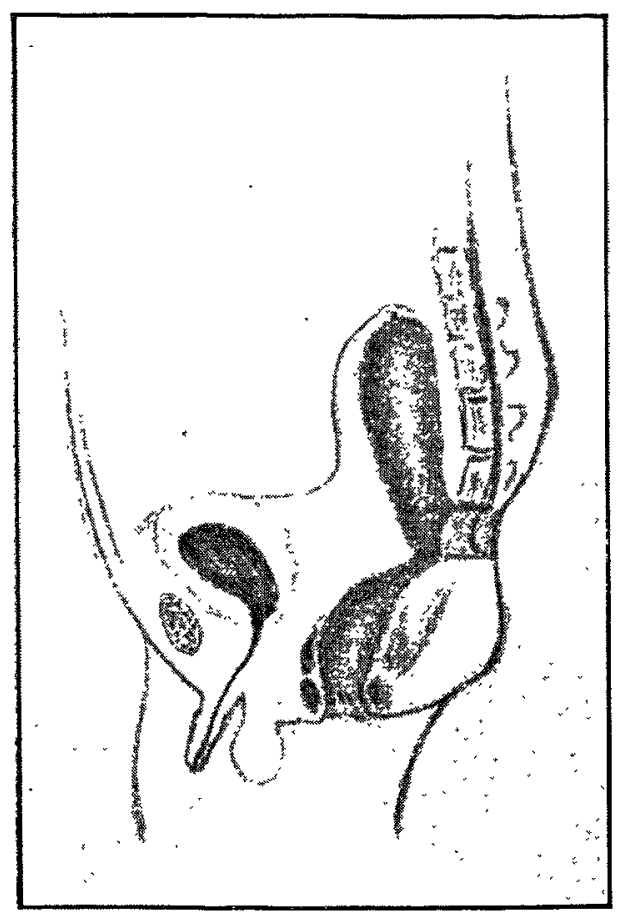

Showing condition after the first operation. Sacral anus formed. Growth removed.

Operation was performed on Jan. 28th. The patient was anæsthetised and the rectum was examined. It was then found that the growth was freely moveable and that the upper limit could be felt. A skin incision was made from 
the fourth sacral spine to the tip of the coccyx and all structures were divided down to the bone. The coccyx was removed but the sphincters were left untouched and a portion of the sacrum was taken away by bone forceps. The rectum was freed above and below the growth, the perito-

FIG. 3.

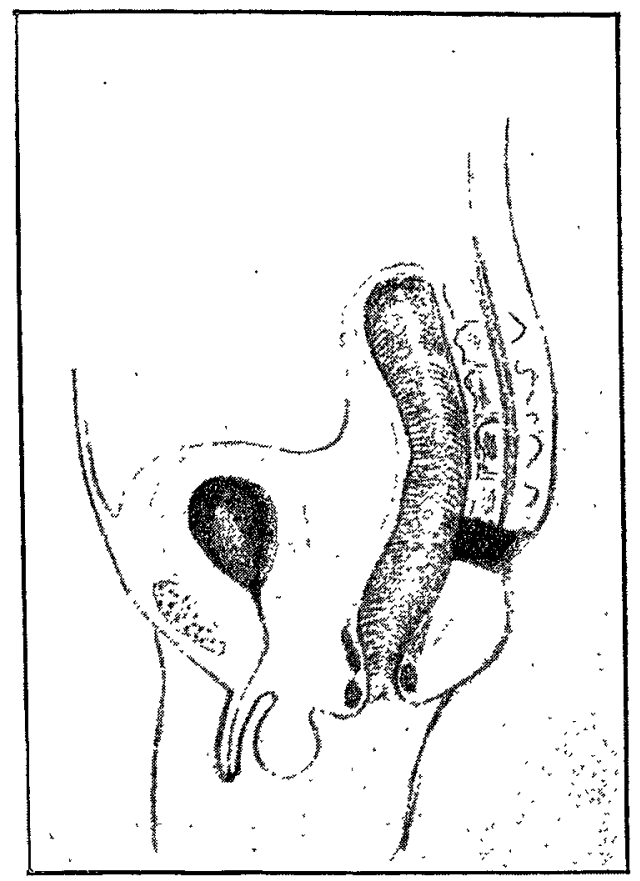

Showing present condition. Sacral anus closed. Upper part of rectum brought down to anal margin. Sphincters intact.

neum being freely openerl. A stout silk ligature was passed round the bowel above the growth and the rectum was divided and turned down and again divided below the growth, about three inchts of bowel being removed. The two ends could not be united, but one or two sutures approximated the cut surfaces anteriorly and then the upper end was sutured to the sacral opening. The remainder of the incision was closed with silkworm-gut sutures after the wound had been thoroughly irrigated with hot hazeline solution and packed with iodoform gauze. A large tube was passed into the bowel and packed round with iodoform gauze. The operation was remarkably free from hæmorrhage, the bleeding being largely controlled by swabs saturated with hot hazeline solution. The patient made a good recovery and left the hospital three weeks later with a sacral opening.

He was readmitted on May 9th, when an ineffective attempt was made to close the sacral opening by freeing the edges of the mucous membrane and suturing the mucous membrane posteriorly, approximating the skin edges and leaving a gauze drain in. This all broke down and he left the hospital in much the same condition as when admitted. He was admitted again on Oct. 10th as the want of control caused him great mental distress. Operation was performed on the 13th. The bowel was freed from its attachment round the sacral opening and separated upwards for about three inches, the peritoneum being again freely opened. The distal part of the mucous membrane between the anus and the sacral opening was entirely removed and the bowel was brou ght down to the anus and stitched to the skin. The patient made an excellent recovery with the exception that on the eighth day he had a bad rigor and a rise of temperature to $105 \cdot 6^{\circ} \mathrm{F}$. During the rigor the bowels acted freely. This was the first action since the operation. He has now to $a^{\prime} l$ intents and purposes a normal rectum with perfect sphincteric control and is in excellent health.

The following points are of practical interest: (1) The control of the hæmorrhage by means of hot hazeline solution of the strength of one $\mathrm{drachm}$ to the pint at a temperature of about $100^{\circ} ;(2)$ the wound was irrigated twice daily after the first 48 hours with either saline or boric solution (this I make a routine custom in all operations for rectal carcinoma); (3) as few stitches as possible were applied to the approximated edges in order that drainage might be as free as possible ; (4) the greatest care was taken to divide the bowel well above the growth and when possible well below it and to avoid infecting the wound from the bowel (this was avoided by ligatures and guards); (5) the patient sat up in bed as soon as possible for better drainage from the wound ; and (6) the fact that perfect control and practically normal sensation were obtained after such an operation is particularly interesting, having regard to the statements which are made as to the loss of sensation following excision of the lining membrane of the anus.

IIarley-street, W.

ON THE ABSENCE OR MARKED DIMINUTION OF FREE HYDROCHLORIC ACID

IN THE GASTRIC CONTENTS, IN MALIGNANT DISEASE OF
ORGANS OTHER THAN
THE STOMACH

BY BENJAMIN MOORE, M.A., D.Sc., JOHNSTON PROFESSOR OF BIO-CHEMISTRY IN THE UNIVERSITY OF LIVERPOOL;

IN COLLABORATION WITH

W. ALEXANDER, M.D., M.CH. R.U.I., F.R.C.S. ExG., HONORARY SURGEON, ROYAL SOUTHERN HOSPITAL, LITERPOOL;

R. E. KELLY, M.B., B.CH., B.Sc. VICT., ALEXANDFR FELLOW, UNIVERSITY OF IIVERPOOL; AND

H. E. ROAF, M.B. Toronto,

JOHNSTON COLONIAL FELLOW, UNIVERSITY OF LIVERPOOL.

IT is well known that free hydrochloric acid is absent in nearly all cases of cancer of the stomach. This was first noticed by Reinhard von den Velden ${ }^{2}$ in 1879 and has been the subject of much observation and criticism since then but may now be taken as a well-established fact. For example, Osler ${ }^{3}$ records that in 94 cases of cancer of the stomach in which the contents were examined free hydrochloric acid was absent in 84 cases. The absence of the free hydrochloric acid has till now chiefly been studied as a diagnostic sign in doubtful cases of cancer of the stomach and has scarcely been considered from any other standpoint. The presence of free hydrochloric acid in a small percentage of cases of cancer of the stomach, as well as the undoubted absence or diminution of the acid in other conditions of the organ or in general disease arising from other causes than cancer, take away greatly from the value of the absence of free hydrochloric acid as a diagnostic sign in doubtful cases suspected of being carcinoma ventriculi. While the abore statement may be freely admitted the observed fact remains that in 90 per cent. or over of cases of cancer of the stomach there is no free hydrochloric acid or the acid is reduced to a minimal trace.

Looking away entirely from the question of diagnosis, this is one of the few established pieces of knowledge that we possess regarding cancer and the cause of the absence of the acid deserves careful inquiry on its own account, since knowledge of this may increase our information regarding the disease with which it is associated. Local conditions in the stomach itself have hitherto been made to furnish explanations of the absence of the acid in the gastric secretion in cases where a cancerous growth has invaded that organ. Such growths in many cases are situated in the pylorie region and in process of growth begin to constrict the exit from the stomach. The consequences are dilatation and retention of food in the stomach which causes continued irrita. tion of the secreting mucous membrane and this in time alters the normal character of the secretion which in the end ceases to be acid and becomes simply a catarrhal secretion. Hence the absence of acid, as in long-continued irritation of the mucous membrane by any other means, is due to chronic gastritis giving rise to a catarrhal flow. That this view, which is the usual one with regard to the absence of the acid, does not exactly fit the known facts is seen from the

1 Abstract of a paper communicated to the Royal Society on Feb. 28th and read on March 16 th, 1905.

2 Deutsches Archiy fïr Klinische Medicin, vol. xxiii., 1879, p. 31

3 Principles and Practice of Medicine, third edition, p. 491 . 